Int. J. Dev. Biol. 52: 627-636 (2008)

doi: $10.1387 / \mathrm{ijdb} .072537 \mathrm{ar}$

\title{
Self-incompatibility systems: barriers to self-fertilization in flowering plants
}

\author{
ANNE C. REA and JUNE B. NASRALLAH* \\ Department of Plant Biology, Cornell University, Ithaca, NY, USA
}

\begin{abstract}
Flowering plants (angiosperms) are the most prevalent and evolutionarily advanced group of plants. Success of these plants is owed to several unique evolutionary adaptations that aid in reproduction: the flower, the closed carpel, double fertilization, and the ultimate products of fertilization, seeds enclosed in the fruit. Angiosperms exhibit a vast array of reproductive strategies, including both asexual and sexual, the latter of which includes both self-fertilization and cross-fertilization. Asexual reproduction and self-fertilization are important reproductive strategies in a variety of situations, such as when mates are scarce or when the environment remains relatively stable. However, reproductive strategies promoting cross-fertilization are critical to angiosperm success, since they contribute to the creation of genetically diverse populations, which increase the probability that at least one individual in a population will survive given changing environmental conditions. The evolution of several physical and genetic barriers to self-fertilization or fertilization among closely related individuals is thus widespread in angiosperms. A major genetic barrier to self-fertilization is self-incompatibility (SI), which allows female reproductive cells to discriminate between "self" and "non-self" pollen, and specifically reject self pollen. Evidence for the importance of $\mathrm{SI}$ in angiosperm evolution lies in the highly diverse set of mechanisms used by various angiosperm families for recognition of self pollen tube development and preventing self-fertilization.
\end{abstract}

KEY WORDS: plant reproductive barrier, pollination, pollen-pistil interaction, $S$ locus

\section{Introduction}

As for all organisms, reproductive success is critical for survival in plants. All plants have the capacity to reproduce sexually, but given their predominantly sessile lifestyle, it is no wonder that plants have maintained the ability to reproduce without the need for a mate throughout their evolutionary history. Most plant species, but very few animal species, have the capacity to reproduce asexually. Even the most evolutionarily advanced and successful group of plants, the angiosperms (flowering plants), are capable not only of reproducing asexually, but can reproduce sexually via self-fertilization, whereby the egg and sperm from the same plant fuse to produce viable offspring. Hermaphroditism, the condition in which an individual has both male and female reproductive structures, is a pre-requisite for self-fertilization. This condition and the ability to self-fertilize are relatively rare in animals but very common in plants.

While self-fertilization has its advantages under favorable and relatively stable conditions, it can be problematic in more variable and unpredictable environments. Since self-fertilization ultimately results in the production of genetically identical offspring, it can culminate in a population of low genetic diversity, making the perpetuation of populations difficult in the variable environments that plants encounter in nature and often cannot escape. It is therefore not surprising that throughout their history, plants have evolved many different mechanisms for preventing self-fertilization, or at least promoting cross-fertilization, which allow them to avoid the potentially deleterious consequences of inbreeding.

In this review, we outline the unique features of fertilization in flowering plants. We focus on the events that precede egg-sperm fusion, namely the intricate interactions that occur between pollen

\footnotetext{
Abbreviations used in this paper: ARC1, Armadillo repeat-containing protein 1; AtPUB8, Arabidopsis thaliana plant U-box protein 8; MAPK, mitogenactivated protein kinase; MLPK, $M$-locus protein kinase;

SBP, S-protein binding protein; SCR, S-locus cysteine-rich protein; SI, selfincompatibility; SP11, S-locus protein 11; SRK, S-locus receptor kinase; SRNase, $S$-locus ribonuclease; THL1/2, thioredoxin $h$-like protein 1 and 2.
}

*Address correspondence to: June B. Nasrallah. Department of Plant Biology, Cornell University, Ithaca, NY 14853, USA. e-mail: jbn2@cornell.edu

Published online: 4 July 2008

$0214-6282 / 2008 / \$ 35.00$

(C) UBC Press

Printed in Spain 
and pollen tube (which carry the haploid male gametes) on the one hand, and diploid cells of the pistil (the female reproductive structure that harbors the haploid female gametes) on the other hand. These highly orchestrated interactions are critical determinants of reproductive success in flowering plants and as a consequence, they have been primary targets in the evolution of reproductive barriers that promote out-crossing.

\section{Successful fertilization: crucial structural features \& events}

\section{Gametophyte development, pollination and double fertiliza- tion}

A distinguishing feature of plants (excluding many algae, which some botanists consider to be plants) is alternation of generations, a life cycle in which plants alternate between a multicellular diploid generation (the sporophyte) and a multicellular haploid generation (the gametophyte). The sporophyte undergoes meiosis to produce haploid spores, which in turn undergo mitosis to produce gametophytes. Gametophytes undergo mitosis to produce haploid sperm cells and egg cells, the fusion of which produces a single-celled diploid zygote that undergoes mitosis to produce the new sporophyte. Throughout plant evolutionary history, there has been a trend toward a dominant sporophyte generation, accompanied by a highly reduced gametophyte. In the flowering plants, the female gametophyte (megagametophyte; embryo sac) is completely dependent on the sporophyte for nutrition and protection. The male gametophyte (microgametophyte; pollen grain) is initially dependent on the sporophyte during its development, but is then released from the sporophyte, and is often dispersed, via wind or animal vectors, ideally to other plants of the same species.

A key evolutionary innovation that distinguishes angiosperms from all other major plant groups is the evolution of the flower. Although this simple yet elegant sporophytic reproductive structure can take many forms, it often consists of four distinct floral organ types arranged in four concentric whorls: on the outside are the sepals, which protect the developing flower, followed by the petals, which function as attractive agents for pollinators, and the stamens and carpels, which are, respectively, the specialized male and female floral organs that house the spores and the gametophytes that develop from them (Fig. 1). The stamen consists of a stalk-like filament supporting an anther, which houses the pollen grains (the male gametophyte) in two pairs of pollen sacs (Fig. 1). A single structure consisting of one carpel, or several fused carpels, is informally called a pistil, and consists of a stigma, style, and ovary (Fig. 1). The apical stigma receives pollen, the style serves as an intermediary conduit between the stigma and the ovary, and the ovary houses the ovules, each of which contains an embryo sac (the female gametophyte).

As in other sexually reproducing organisms, plant gametes are produced by meiotic division of diploid progenitor cells, but they are packaged in unique ways. In the anther, each of the haploid products of meiosis develops into a pollen grain having dual gametophytic/sporophytic (haploid/diploid) features: an interior consisting of haploid cells (two or three, depending on the species) derived by mitotic division of the primary meiotic product, and a diploid-encoded exterior coat consisting largely of lipids, carbohydrates, and proteins derived from the diploid nurse cells of the tapetum, a specialized secretory cell layer that lines the pollen sac. At maturity, pollen grains, released by dehiscence of the anthers, are in effect free-living gametophytes, which contain not only the sperm cells that participate in fertilization, but also a vegetative cell that supports the germination and growth of the pollen tube as it journeys within the pistil towards the ovary (for a review of pollen development, see McCormick, 2004). In the pistil, meiosis occurs within ovules buried deep inside the ovary and produces, after several mitotic divisions, a haploid embryo sac consisting of seven cells, among which a uninucleate egg cell and a binucleate central cell participate in fertilization. The embryo sac is protected by diploid tissues of the ovule, which form a discontinuous layer surrounding the embryo sac with an opening near the egg cell for pollen tube entry (see Reiser and Fischer, 1993 and Yadegari and Drews, 2004 for reviews of embryo sac development).

Once a pollen tube enters the embryo sac, it releases its cargo of two sperm cells which effect double fertilization, an evolutionary adaptation unique to angiosperms: one sperm cell fuses with the egg cell to create a diploid zygote that divides by mitosis to become an embryo, while the second sperm cell fuses with the binucleate central cell to create a triploid endosperm that nourishes the developing embryo. At the culmination of embryo development, the ovule has become a seed, with its surrounding diploid tissues having become the seed coat. At maturity, the ovary develops into the fruit, yet another reproductive feature unique to angiosperms, which serves to protect the seed(s) and often functions in seed dispersal. Angiosperms are so-named according to this adaptive advantage of a protected seed: the word "angiosperm" comes from the Greek words angeion ("vessel") and sperma ("seed") (Raven et al., 2005).

Double fertilization is only the last of many steps that are critical for reproductive success in flowering plants. The development of male and female gametes in physically separate structures, even in hermaphroditic flowers, and the fact that female gametes are enclosed deep within the ovary mean that, for fertilization to occur, the pollen tube must grow across the many layers of diploid cells in the pistil, often traversing long distances at high speed. For example, the maize pollen tube elongates at the astounding speed of $4-10 \mathrm{~mm} / \mathrm{h}$ (Booy et al., 1992) through the long silk of the maize pistil. The pollen tube is not filled with cytoplasm along its length; rather, the cytoplasm is confined to the growing tube tip as a result of $\beta-1,3$ glucan (callose) "plugs" akin to fungal septa, which are deposited at regular intervals and separate the cytoplasm from the spent pollen grain and older part of the tube.

The successful journey of the pollen tube towards its ovule targets is dependent on its intricate and highly regulated interactions with diploid cells of the female reproductive apparatus. These interactions occur at all stages of pollen tube development, starting with adhesion and hydration of the pollen grain and germination of the pollen tube at the stigma epidermal surface, continuing with intercellular growth through specialized tissue (called the transmitting tract) in the stigma, style, and ovary, and ending with pollen tube entry into the ovule. In view of these interactions, the pistil acts not only as a passive conduit for pollen tubes, but also as a pre-fertilization selective sieve for screening the many pollen grains from various sources that bombard it, allowing the germination and growth of appropriate grains and preventing the development of inappropriate grains. In this capac- 
Fig. 1. Hermaphroditic flowers of the Brassicaceae family. (A) A flower of the Brassica genus, which includes the cole crops such as broccoli, cabbage, brussel sprouts, and oilseed rape (canola). The yellow petals, displayed in the cruciform pattern that gives the family its "crucifer"

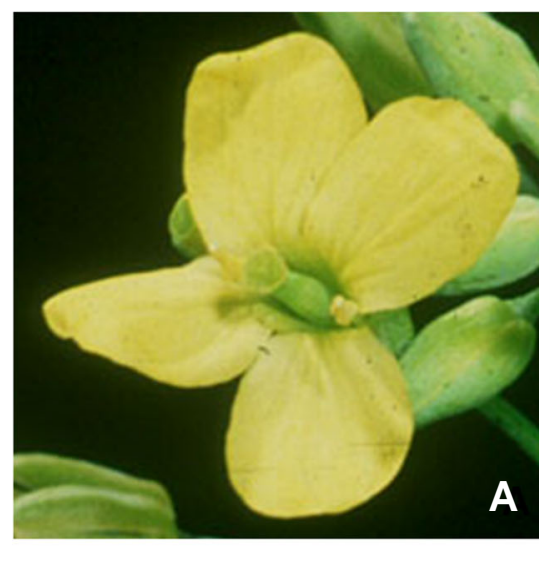
common name, surround the centrally-located female (pistil) and male (stamens) reproductive organs. (B) A scanning electron micrograph of an Arabidopsis thaliana flower, focusing in on the pistil and stamens. The pistil is subdivided into the apical stigma, which receives and screens pollen, the style, through which pollen tubes grow, and the ovary, which houses the ovules. The stamen consists of an apical anther, which houses the pollen, supported by a stalk-like filament. Several mature pollen grains have shed from the anthers. (C,D,E) The path of pollen tube growth in an A. thaliana pistil. In these epifluorescence images, the fluorescence of pollen tubes (arrowheads) is due to binding of the aniline blue stain to polysaccharides in the tube wall. Pollen grains land on the stigma epidermal cells and if determined compatible by the stigma, they form sperm-cellcontaining pollen tubes that grow between sub-epidermal cells of the stigma and are guided down the style (C)

and ovary (D). In the ovary, a pollen tube is guided by unknown cues towards an ovule (E), into which it discharges its two sperm cells, which subsequently fuse with embryo sac cells within the ovule in the process of double fertilization (see text). Scale bars, $100 \mu \mathrm{m}(C, D), 20 \mu m$ (E).

ity, the pistil is central to preventing non-productive and energetically wasteful inter-specific egg-sperm fusions. Additionally, the pistil can function as an intra-specific pre-zygotic barrier to fertilization, as occurs in plants that exhibit genetic self-incompatibility.

\section{Pre-zygotic genetic barriers to self-fertilization}

Genetic diversity is vital to the long-term success of populations, as it increases the probability that at least one individual in a population will survive in the face of drastic environmental fluctuations. Angiosperms have evolved many methods of avoiding self-fertilization and thus inbreeding, thereby promoting outcrossing and increasing genetic diversity. Some angiosperms exhibit unisexual male and female flowers that may be located on separate plants (as in holly), which precludes self-fertilization, or on the same individual (as in maize), which reduces but does not prevent self-fertilization. The majority of angiosperms, however, have hermaphroditic flowers in which male and female organs develop coordinately in close proximity to each other. In some of these plants (e.g., sugar maple), differential timing of anther and stigma maturation promotes out-crossing by drastically reducing opportunities for self-fertilization. In others, self-fertilization is prevented and out-crossing is ensured by self-incompatibility systems that discriminate between genetically-related (self) and genetically unrelated (non-self) pollen grains.

\section{Self-incompatibility}

Of the $\sim 250,000$ species of angiosperms, more than half have evolved self-incompatibility (SI) (de Nettancourt, 2001). It should be noted from the outset that the term "self-incompatibility" refers to a variety of molecularly diverse and evolutionarily unrelated mechanisms for preventing self-fertilization. In some self-incompatible species, differences in floral morphology act to reinforce the ability of the pistil to discriminate between self and non-self pollen. For example, primrose (Primula) exhibits two floral forms (morphs) that differ in morphology, primarily in the relative placement of stigmas and anthers, and pollinations succeed only between different morphs (de Nettancourt, 2001). It is this visually dramatic floral heteromorphism and its association with the ability to cross-pollinate that allowed Darwin and other early botanists to appreciate the existence of self-incompatibility in plants (Darwin, 1876; de Nettancourt, 2001). However, in most plant groups, $\mathrm{SI}$ is not accompanied by differing floral morphology and the outcome of pollination can only be predicted by reciprocal pollination tests between individual plants. Even among these so-called homomorphic SI systems, there are major differences among families in the number of self-recognition loci that control SI specificity, the genetic control of pollen SI phenotype (i.e., whether it is determined by its own haploid genome or the diploid genome of its parent plant), as well as where along the path of pollen tube growth (stigma, style, or ovary) self-pollination is inhibited and the molecular mechanism that underlies arrest of self pollen. These differences among SI systems suggest that SI has evolved multiple times throughout angiosperm history.

Despite these differences, however, all SI systems analyzed to date, irrespective of their underlying molecular mechanisms, share several features in common. In many systems, including those described below, SI specificity is determined by haplotypes of a single self-recognition locus, traditionally termed the $S$ (Sterility) locus. In this context, "self" and "non-self" refer, respec- 
tively, to genetic identity and non-identity at the $S$ locus. In all SI systems characterized to date, the $S$ haplotype consists of two genes, which individually determine SI specificity in pistil or pollen. These genes are highly polymorphic due to strong balancing selection, and a self-incompatible species can exhibit a large number of $S I$ recognition specificities, and therefore of $S$ haplotypes: e.g., 100 different SI specificities are estimated to occur in Brassica rapa(Watanabe et al., 2000). The SI recognition genes are maintained in tight genetic linkage by reduced recombination, resulting from close physical proximity of the genes and from the extensive structural heteromorphism (rearrangements and haplotype-specific sequences) that distinguish different $S$ locus haplotypes (Nasrallah, 2000). In all systems, recognition of self pollen is based on allele-specific interactions (direct or indirect) of the pistil- and pollen-expressed products of $S$ tocus genes, which in turn trigger activation of a cellular response in pistil or pollen (depending on the SI system), which culminates in inhibition of pollen tube development. Thus, unlike other recognition phenomena, which are typically based on recognition and rejection of non-self, SI systems are based on recognition and rejection of self.

\section{A variety of molecular mechanisms for inhibition of self- pollination}

To date, the outlines of three molecular mechanisms of selfpollen recognition and inhibition have been elucidated by molecular analysis of only a handful of plant families: the crucifer family (Brassicaceae, including cabbage, broccoli, oilseed rape/canola), the night-shade family (Solanaceae, including tobacco, tomato, potato, petunia), the rose family (Rosaceae, including fruit trees), the snapdragon family (Scrophulariaceae), and the poppy family (Papaveraceae). These systems differ from one another with respect to both the recognition and response phases of SI. In particular, the manner in which self pollen is arrested and whether this arrest involves cell death or not is dictated by the site of pollen inhibition, i.e., whether it occurs early or late during the pollen tube's journey through the pistil, which in turn is determined by characteristics of the stigma surface. Thus, in crucifers, the SI response is manifested at the surface of the "dry" (i.e., nonsecretory) stigma by failure of pollen germination and tube growth; as a consequence, incompatible pollen tubes rarely grow into the pistil and it stands to reason that their inhibition would not be accompanied by death of the pollen grain or tube. In contrast, pollen tube death is clearly the only way to inhibit incompatible pollen tubes that have already penetrated into the pistil, as occurs in families having a "wet" (i.e., highly secretory) stigma on which pollen grains automatically hydrate and germinate. It may be argued that SI mechanisms operating at the stigma surface are more efficient, energetically and reproductively, than those operating in the transmitting tract of the stigma, style, and ovary, if only because they preclude the formation of incompatible pollen tubes, which can clog the transmitting tract and interfere with the subsequent growth of compatible pollen tubes.

Early arrest of self pollen: recognition by receptor-ligand interactions at the stigma surface in the crucifer family

The SI system of crucifers operates at the level of interaction between a pollen grain and a stigma epidermal cell. The SI response is very rapid and is typically observed within minutes of pollen-stigma contact. It is also highly localized and involves only the zone of contact between a pollen grain and a stigma epidermal cell. As a result, a single papillar cell can discriminate between genetically different pollen grains, inhibiting a self pollen grain while allowing the development of a non-self pollen grain (Dickinson, 1995). Furthermore, incompatible pollen grains that have not formed pollen tubes are still viable for a time after landing on an incompatible stigma, and can form pollen tubes when transferred to a compatible stigma (Geitmann, 1999). Thus, inhibition of self pollen in this family does not involve cell death of either pollen or stigma cells.

Consistent with these features, recognition of self-related pollen in crucifers is based on the action of cell surface-localized receptors and ligands encoded by two $\mathcal{S}$-locus genes: the $\underline{S}$ tocus Receptor Kinase (SRK) gene, which encodes a single-pass transmembrane serine/threonine kinase localized in the plasma membrane of the stigma epidermal cell (Stein et al., 1991, 1996; Takasaki et al., 2000), and the $\underline{S}$ tocus $\underline{\text { Cysteine-Rich protein }}$ (SCR) gene (Schopfer et al., 1999; also designated $S P 11$ ( $\underline{S}$ locus protein 11; Suzuki et al., 1999)), which encodes a small peptide that is located in the pollen coat and functions as the ligand for the SRK receptor. Contact between a pollen grain and a stigma epidermal cell causes transfer of the SCR peptide, along with other components of the pollen coat, to the stigma surface, allowing SRK-SCR interactions to take place. SRK and SCR are highly polymorphic: overall amino acid sequence among alleles can diverge by as much as 35\% for SRK and by over $70 \%$ for SCR variants. And it is the specific and direct interactions between SRK and SCR variants encoded by the same Shaplotype that underlie the specific recognition of self pollen (Kachroo et al., 2001; Takayama et al., 2001; Shimosato et al., 2007). The conclusion that SRK and SCR are necessary and sufficient for specific recognition of self pollen has been demonstrated repeatedly by analysis of loss-of-function mutants and by gain-of-function transgenic experiments in which transfer of a particular allele of $S R K$ or SCR resulted in acquisition of the corresponding SI specificity in stigma or pollen, respectively (Nasrallah, 2005; Takayama and Isogai, 2005). One of the most dramatic transgenic experiments was the successful inter-specific transfer of the SI trait by transformation of the self-fertile model plant Arabidopsis thaliana with an $S R K-S C R$ gene pair from the self-incompatible $A$. Iyrata (Nasrallah et al., 2002, 2004).

The current view of SI in crucifers is based on the ligandactivated receptor paradigm established in animal systems, whereby the binding of SCR to the extracellular domain of SRK activates the receptor's kinase, initiating a signaling cascade within the stigma epidermal cell that culminates in pollen rejection (Fig. 2). In this view, all biochemical activity triggered by the SRKSCR interaction is thought to occur within the stigma, with the pollen grain contributing only the activating ligand. However, and although supported by the fact that pollen grains remain viable after contacting an incompatible stigma, this notion has not been rigorously tested.

The molecules that regulate or orchestrate the SI response downstream of stigma-pollen recognition are poorly understood. Efforts at elucidating the SI signaling pathway have involved yeast 2-hybrid screens for proteins that interact with the kinase domain of SRK (Bower etal., 1996; Gu etal., 1998; Vanoosthuyse et al., 2003) and analysis of mutations that cause breakdown of 
SI, not only in naturally self-incompatible Brassicaspecies (Murase et al., 2004), but also in the $A$. thalianatransgenic self-incompatible model (Liu et al., 2007). These approaches have identified a few potential candidate effector proteins, only some of which have been shown to function in SI. Two thioredoxin $h$-like proteins, identified in yeast (Bower et al., 1996), are thought to function as negative regulators of $\mathrm{SI}$ by maintaining SRK in an inactive form in resting stigmas, i.e., in the absence of SCR ligand. Antisense suppression of these proteins causes low-level constitutive rejection of both self and non-self pollen (Haffani et al., 2004). Furthermore, a constitutively active variant of SRK is inhibited by thioredoxin, and this inhibition is reversed by addition of self pollen coat proteins (Cabrillac et al., 2001). Interestingly, in the stigma, SRK forms dimers in the absence of SCR (Giranton et al., 2000) via ligand-independent association domains located in its extracellular region (Naithani et al., 2007), suggesting that thioredoxin $h$-like proteins might function to maintain these ligandindependent dimers in an inactive form and that this inhibition would be relieved by interaction of SRK with its cognate SCR (Cabrillac et al., 2001). Whether activation of SRK is also accompanied by the formation of higher order receptor complexes or changes in the conformation of the receptor, as described for animal receptors, is not known.

Three positive effectors of the SI response have been identified. MLPK (M-locus Protein Kinase), which was identified by map-based cloning of a Brassica rapa mutation that disrupts the ability of the stigma to inhibit self pollen, is a cytosolic serine/ threonine protein kinase with a putative $\mathrm{N}$-terminal myristoylation signal that presumably anchors it to the stigma plasma membrane (Murase et al., 2004). Another positive effector is Brassica ARC1 (Armadillo Repeat-Containing protein 1; Gu et al., 1998), a member of the sub-family of U-box proteins that exhibit E3 ubiquitin ligase activity and contains the Armadillo (Arm) repeat protein interaction domain (Azevedo et al., 2001; Stone et al., 2003). ARC1 is expressed specifically in stigmas, it interacts in yeast with phosphorylated forms (but not unphosphorylated forms) of the SRK kinase domain (Gu et al., 1998), and it localizes with the proteasome and COP9 signalosome only in the presence of a functional SRK (Stone etal., 2003). Finally, AtPUB8(Arabidopsis thaliana $\underline{\text { Plant }} \underline{\mathrm{U}}$ - box protein 8 ) was identified using the $A$. thaliana transgenic SI model as a gene required for expression of SI at late stages of stigma development, apparently by regulating the levels of SRK transcripts (Liu et al., 2007). Like ARC1, AtPUB8 is predicted to have both a U-box domain and an Arm-repeat region (Azevedo et al., 2001) and to have E3 ligase activity, but it lacks several domains found in $A R C 1$, suggesting that it is not the functional ortholog of Brassica ARC1.

Despite this progress in identifying some effectors of the $\mathrm{SI}$ response, we are far from even a rudimentary understanding of the cellular events that are triggered by SCR-mediated activation of SRK. The nature of the identified effector proteins is consistent with a role for both phosphorylation (as expected) and ubiquitination in the regulation or orchestration of the SI response. However, the targets of MLPK kinase activity and of ARC1 and AtPUB8 E3 ligase activity are not known, and only a vague outline of SRK signaling may be sketched at this time (Fig. 2). One scenario

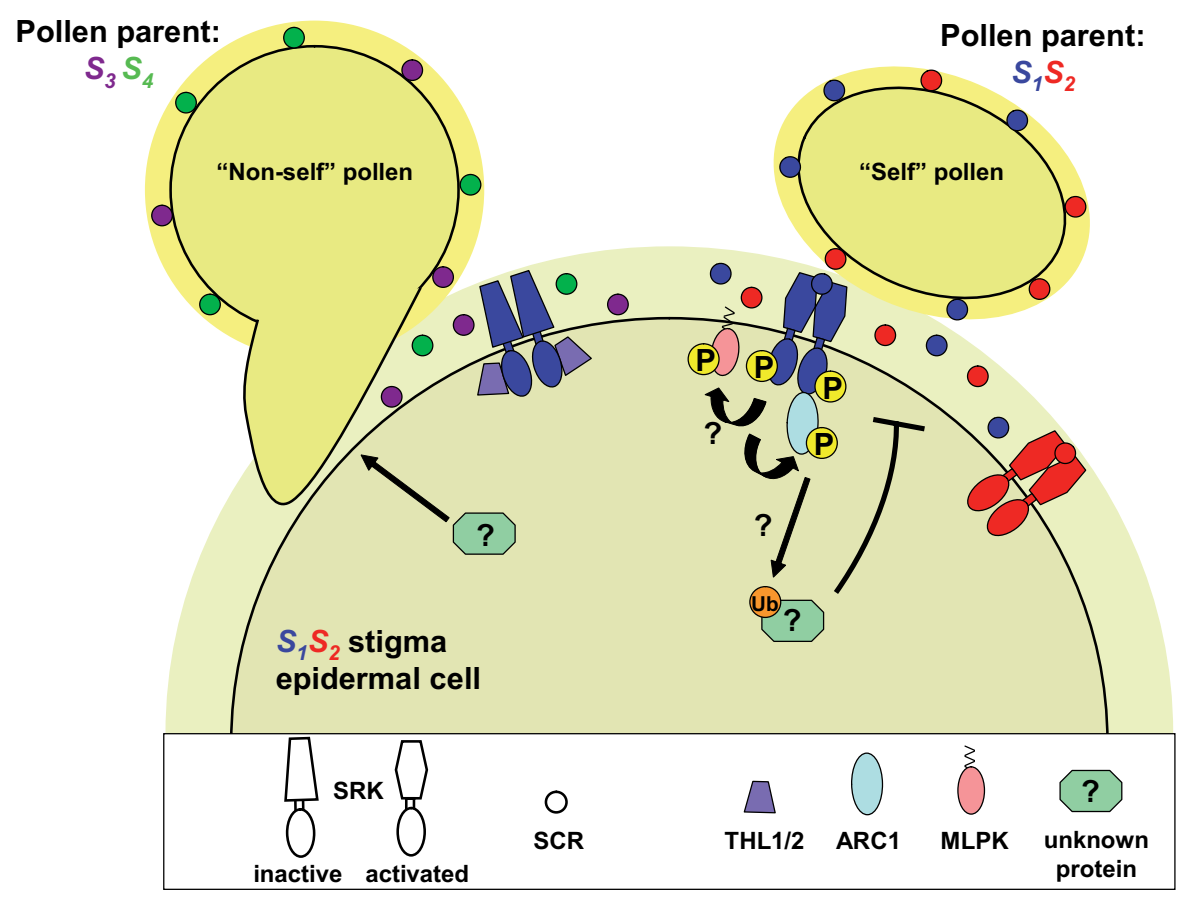

Fig. 2. Receptor-mediated recognition of self and stigmatic inhibition of pollen tube development in self-incompatible crucifers. The diagram shows an $\mathrm{S}_{1} \mathrm{~S}_{2}$ stigma epidermal cell interacting with a pollen grain derived from an $\mathrm{S}_{1} \mathrm{~S}_{2}$ plant (self pollen) and a pollen grain derived from an $\mathrm{S}_{3} \mathrm{~S}_{4}$ plant (non-self pollen). The SI self-recognition molecules, the stigma SRK receptor and the pollen coat-localized SCR ligand, are color-coded to depict variants with different SI specificities. Pollen grains are shown to display two SCR variants because self-incompatible plants are typically heterozygous at the S locus and SCR is produced by tapetal cells, which are derived from diploid cells of the anther: thus, assuming co-dominance of $\mathrm{S}$ haplotypes, the haploid pollen grains produced by an $\mathrm{S}_{1} \mathrm{~S}_{2}$ plant will be phenotypically $\mathrm{S}_{1} \mathrm{~S}_{2}$ even though genotypically they are $\mathrm{S}_{1}$ or $\mathrm{S}_{2}$. SRK is shown as forming ligandindependent homodimers (i.e., in the absence of self pollen), which are maintained in an inactive state by binding to the thioredoxin h proteins THL 1 and THL2. Allele-specific binding of the SRK extracellular domain to its cognate SCR ligand would activate the receptor by dislodging the inhibitory THL proteins and possibly causing a conformational change in the receptor. This activation would then trigger a localized response within the stigma epidermal cell that culminates in the inhibition of a self pollen grain but does not affect the germination of a non-self pollen grain, whose SCR does not bind and activate SRK. Arrows drawn in the cytoplasm of the stigma epidermal cell depict a largely speculative (question marks) signaling pathway that includes only two effectors: the membrane-bound kinase MLPK and the cytoplasmic E3 ligase ARC1, which might ubiquitinate as-yet unknown proteins (either inhibitors of SI or proteins required for pollen tube growth), either causing their degradation or sub-cellular redistribution. Not shown is AtPUB8, another positive effector of SI with predicted E3 ligase activity, which is thought to function largely by regulating the steady-state levels of SRK transcripts. 

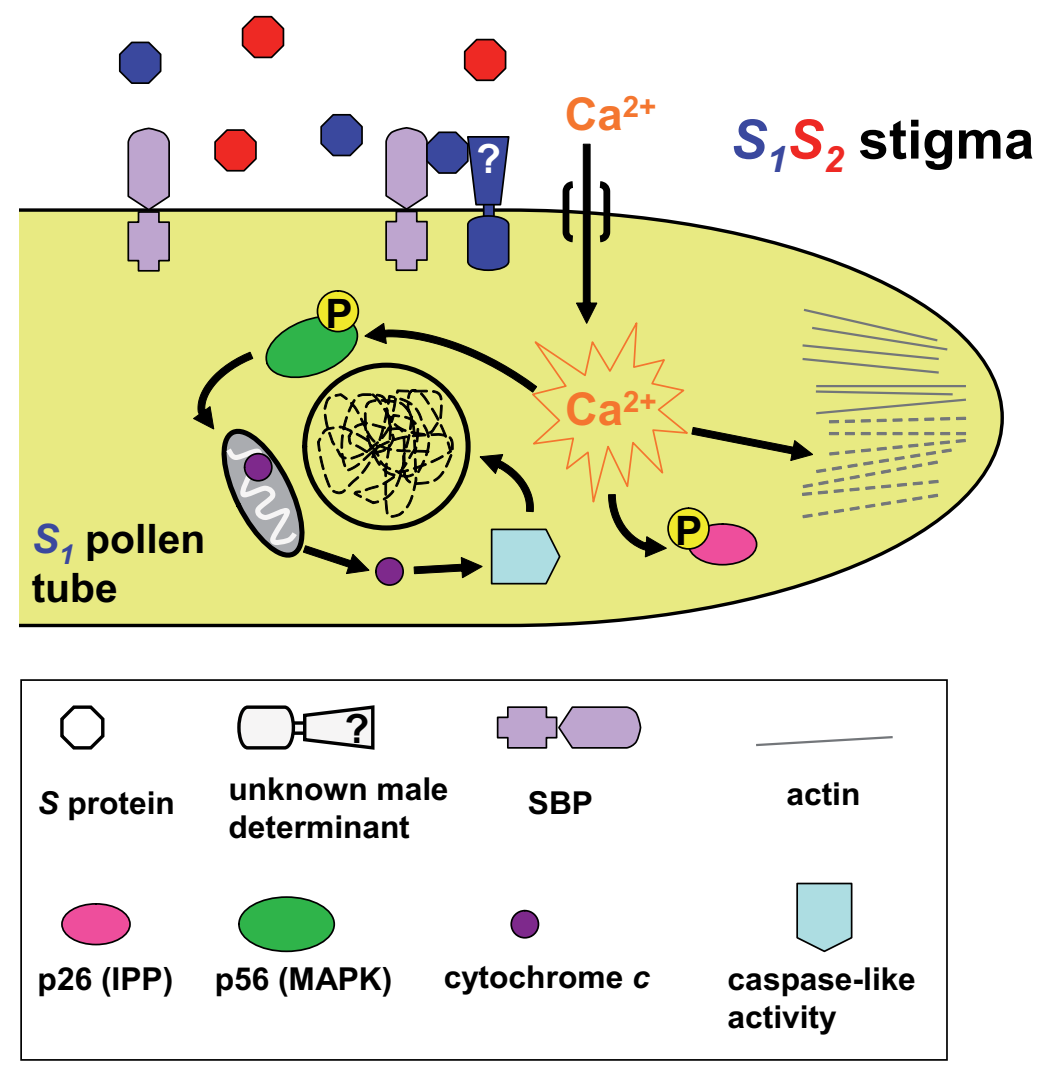

Fig. 3. Programmed cell death of self pollen tubes in the poppy stigma. The diagram shows an $\mathrm{S}_{1}$ (self) pollen tube growing in an $\mathrm{S}_{1} \mathrm{~S}_{2}$ stigma. The diploid cells of the stigma secrete two S-protein variants (represented by different colors) that accumulate in the extracellular matrix through which the pollen tubes grow. The model postulates that the $S$ protein interacts in an allele-specific manner with an as-yet unidentified receptor localized in the pollen tube membrane and encoded by the S locus. Because the SI phenotype of a pollen tube is determined by its own haploid genotype, each pollen tube is shown as expressing one variant of this putative receptor. The interaction between the $S$ protein and its cognate pollen receptor would recruit the accessory pollen tube membrane protein SBP, which somehow initiates opening of calcium channels in the membrane of self pollen tubes and triggers a series of cellular responses that cause death of self pollen tubes. As described in the text, these responses, which have been demonstrated experimentally using an in vitro pollen tube growth assay, include a rapid influx of calcium causing actin depolymerization, disruption of tube metabolism, activation of a MAPK, and culminating in various events characteristic of programmed cell death.

involves on the one hand, a phosphorylation cascade with MLPK as a possible intermediate and on the other hand, ubiquitination causing degradation or subcellular redistribution of unknown proteins, which might function as inhibitors of SI or proteins required for pollen tube growth. As yet, no clues have emerged regarding how these two biochemical activities intersect to cause arrest of self pollen tube development at the stigma surface.

\section{Self incompatibility (SI) by pollen tube cell death: two distinct mechanisms}

In contrast to the early-acting SI system of crucifers, late-acting SI systems, in which incompatible pollen grains germinate and produce pollen tubes that grow into the pistil, typically result in pollen tube death. This phenomenon has been described in two molecularly distinct SI systems: one involving programmed cell death and the other involving degradation of pollen tube RNA.

Programmed celldeath of selfpollen tubes in poppy

The SI response of poppy (Papaver rhoeas) is manifested during or shortly after pollen tube germination at the stigma surface and results in death of pollen tubes after penetration into the stigma (Geitmann, 1999). In contrast to the other two SI systems described here, only the female determinant of SI specificity (the stigma-localized S protein), but not the pollen determinant, has been reported in this SI system. Furthermore, the S protein is a small secreted glycoprotein that does not exhibit sequence similarity to proteins of known function, and its identity does not therefore suggest how it might effect inhibition of self pollen. Nevertheless, an understanding of the biochemical events that occur within self pollen tubes to cause their arrest is much more advanced in this system than in any other SI system. This progress has largely been due to the development of a robust in vitro bioassay for pollen tube growth, in which addition of purified preparations of the $S$ protein faithfully recapitulates the SI response, triggering dramatic cellular responses and ultimate cell death specifically in self pollen tubes (McClure \& Franklin-Tong, 2006). Among the observed effects of self S protein (Fig. 3 ) is a rapid influx of calcium just behind the tube tip, which alters the normal cytosolic tip-focused calcium gradients that maintain growth at the pollen tube tip (Franklin-Tong et al., 2002). This calcium influx apparently triggers several downstream events that cause initial inhibition of pollen tube growth, among the earliest of which are actin depolymerization and disruption of the actin cytoskeleton (Snowman etal., 2002; Thomas etal., 2006). These events are followed by calcium/calmodulin-dependent phosphorylation and inactivation of p26, a 26 $k D a$ cytosolic pollen protein with homology to soluble inorganic pyrophosphatases known to drive biosynthesis reactions (Rudd et al., 1996; de Graaf et al., 2006). Subsequent events include phosphorylation and activation of a putative MAPK (Mitogenactivated protein kinase; Rudd et al., 2003) and several known hallmarks of programmed cell death, such as leakage of cytochrome cfrom mitochondria into the cytosol, activation of caspases (Thomas and Franklin-Tong, 2004), and DNA fragmentation (Jordan et al., 2000).

On the basis of these results, the male determinant of $\mathrm{SI}$ is proposed to be a receptor localized to the plasma membrane of the pollen tube (Fig. 3). This predicted receptor would function primarily as a regulator of calcium channel activity, possibly in conjunction with an accessory receptor, the S-protein binding protein SBP (Hearn et al., 1996). SBP is an integral membrane proteoglycan that is expressed specifically in pollen tubes, binds stigmatic $S$ proteins (albeit not in an allele-specific manner), and apparently enhances the ability of these $S$ proteins to inhibit self pollen tubes in vitro (Jordan et al., 1999). Identification of the male 
determinant of $\mathrm{SI}$ is clearly essential for understanding how it interacts (either directly or indirectly via SBP) with the stigmatic S protein to initiate programmed cell death in self pollen tubes.

\section{SI by cytotoxic $S$-RNases and degradation of pollen tube RNA}

In the nightshade, rose, and snapdragon families, the SI response is typically manifested within the upper third of the style where incompatible pollen tubes exhibit reduced rates of elongation, loss of membrane integrity, disrupted organelles, and wall thickening, all of which can lead to swelling and bursting of the tube tip (Ebert et al., 1989; Lush and Clarke, 1997; de Nettancourt, 2001). This dramatic cessation of pollen tube elongation is effected by the S-RNase ( $S$-locus ribonuclease), an abundant and highly polymorphic pistil-specific glycoprotein encoded by the $S$ locus and secreted into the extracellular matrix that lines the path of pollen tube growth (McClure et al., 1989; Lee et al., 1994; Murfett et al., 1994). The S-RNase has a non-specific RNA degrading activity (McClure et al., 1990), but similar to $S$-locus products in other SI systems, its activity is directed specifically at self pollen tubes: when self pollen tubes grow alongside non-self pollen tubes in a pistil, only self tubes are arrested while non-self tubes continue their growth towards the ovules.

How S-RNases effect this $S$ allele-specific inhibition of self pollen tubes is a major unanswered question. This specificity cannot be ascribed to selective uptake of S-RNase by self pollen tubes because S-RNases are non-specifically taken up by self and non-self pollen tubes alike (Luu et al., 2000). Therefore, specificity must result from events that take place within the pollen tube subsequent to S-RNase uptake. A clue derives from the predicted biochemical activity of the pollen $S$ locus-encoded partner of the S-RNase, SLF ( $S$-locus F-box; Lai et al., 2002; Sijacic et al., 2004) [designated SFB ( $S$-haplotypespecific F-box) in the rose family (Ushijima et al., 2003)]. SLF is a predicted cytoplasmic protein that belongs to the F-box protein family, whose members are known to function as part of an E3 ubiquitin ligase complex. Thus, SLF is thought to function in ubiquitin-mediated proteolysis, with its primary (if not only) target being self S-RNase (i.e., the S-RNase encoded by the same $S$ haplotype). Indeed, SLF binds to E3 ligase complex components (Qiao et al., 2004; Hua and Kao, 2006), and proteasomal inhibitor treatment causes inhibition of compatible, but not incompatible, pollen tubes (Qiao et al., 2004). Furthermore, S-RNase and SLF interact. However, their interaction is not allele-specific, i.e., SLF binds to both self and non-self SRNase (Qiao et al., 2004). As a result, there is still much debate about how these $S$-locus proteins mediate specific RNA degradation and arrest of self pollen tubes.

One scenario is that SLF interacts with any S-RNase that is taken up by the pollen tube, but that only non-self S-RNase molecules are ubiquitinated and degraded, while self S-RNase is protected and remains competent for RNA degradation, either by an additional $S$ haplotype-specific interaction with its cognate SLF or by interaction with a putative unknown mol-

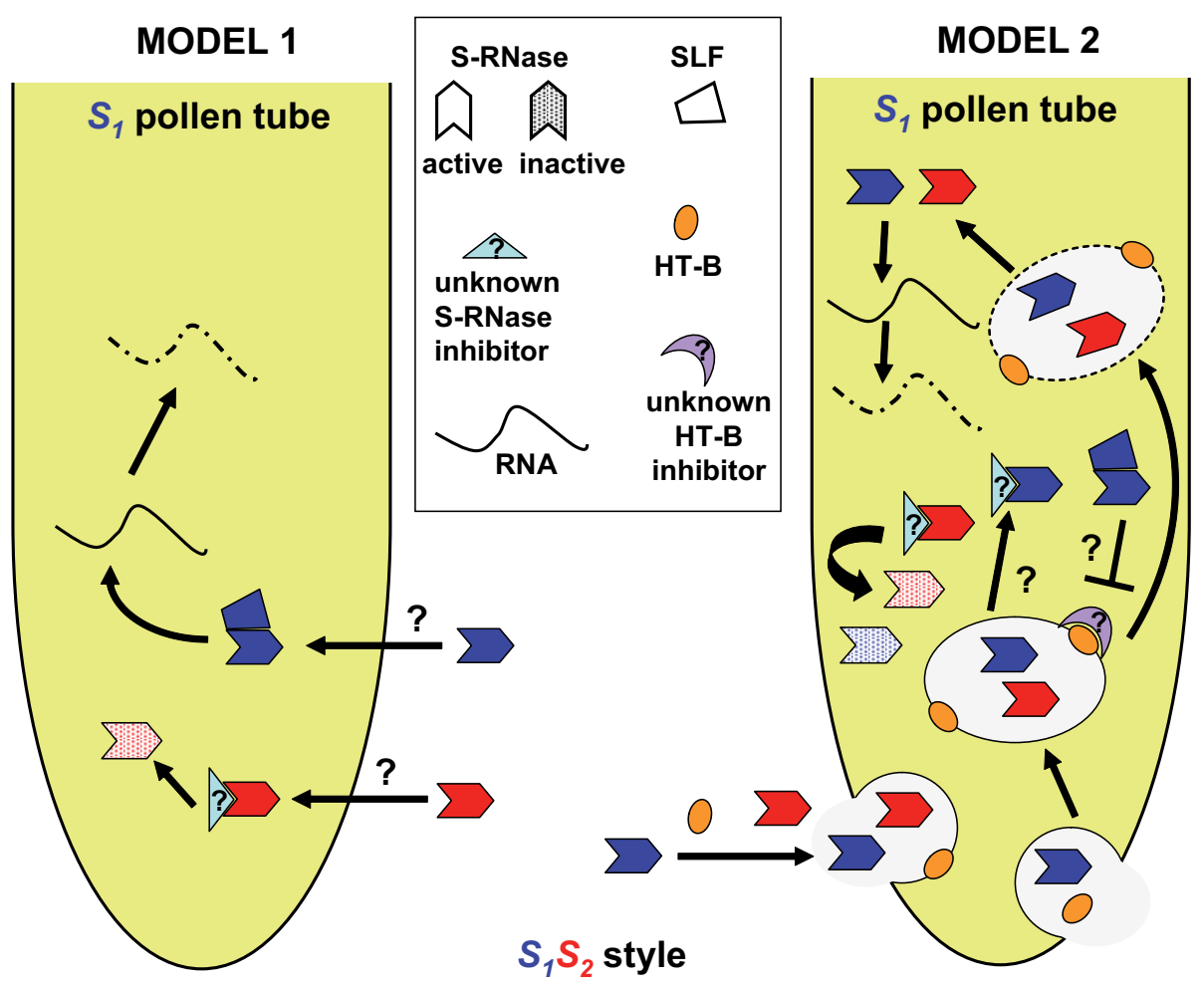

Fig. 4. RNase-based inhibition of self pollen tubes in the style of the nightshade, rose, and snapdragon families. The diagram shows $\mathrm{S}_{1}$ (self) pollen tubes growing intercellularly through the style of an $\mathrm{S}_{1} \mathrm{~S}_{2}$ plant. The diploid style secretes two S-RNase variants (represented by different colors) into the extracellular matrix of the transmitting tract. The S-RNases are taken up non-specifically by pollen tubes, where they interact with their cognate SLF. Each pollen tube expresses one SLF variant encoded its own haploid genotype. Two current models of self pollen tube inhibition are shown, both of which attempt to explain how the cytotoxic action of SRNases is averted in non-self pollen tubes and how the interaction of SLF with its cognate SRNase within the pollen tube results in degradation of cellular RNA in self pollen tubes. (Model 1) postulates the existence of an unknown general S-RNase inhibitor in pollen tubes, which would bind and inactivate $S$-RNases by either sequestering them or causing their degradation. Allele-specific interaction between S-RNase and its cognate SLF would prevent binding of this inhibitor, thus maintaining the S-RNase in an active form that is competent for RNA degradation. (Model 2) is more complex and invokes dynamic changes in the subcellular localization of S-RNases, effected largely by HT-B, a protein that is secreted by the style and is required for SI. As described in the text, the major postulates of this model are: (1) S-RNases are sequestered within vesicular compartments in pollen tubes; (2) in non-self pollen tubes, S-RNases remain sequestered and any that might escape these compartments are eliminated by a general surveillance system; (3) in self pollen tubes, allele-specific S-RNase-SLF interaction would protect the S-RNase from degradation, cause stabilization of HT-B, which in turn would cause disintegration of S-RNase compartments, release of the S-RNases, and RNA degradation. 
ecule. However, deletion of the $S L F$ gene does not cause the constitutive rejection of self and non-self pollen predicted by this scenario (Sonneveld et al., 2005). To accommodate this result, one model of S-RNase-based SI (Fig. 4, Model 1) invokes an unknown S-RNase inhibitor that would inhibit all SRNases by binding to their active site. The interaction of SRNase with its cognate SLF would somehow prevent inhibitor binding, allowing the protected S-RNase to degrade RNA.

A weakness of this model is that it fails to accommodate a role for three stylar proteins known to be required for self pollen tube inhibition: the small, asparagine-rich HT-B protein; the $120 \mathrm{~K}$ glycoprotein, which like S-RNases is taken up nonspecifically into the pollen tube; and factor 4936 (Lind et al., 1996; McClure et al., 1999, 2000; O'Brien et al., 2002; Hancock et al., 2005). It also does not account for the recently observed dynamic subcellular distribution of S-RNases in pollen tubes. It was found that S-RNases are not degraded after uptake into the pollen tube as previously hypothesized; rather, they are sequestered along with $120 \mathrm{~K}$ glycoprotein within endomembrane vesicles in both self and non-self pollen tubes (Goldraij et al., 2006). As pollen tube growth progresses, these S-RNasecontaining compartments break down in self pollen tubes, presumably releasing $\mathrm{S}-\mathrm{RNases}$ into the cytoplasm, but they remain intact in non-self tubes. Loss of HT-B, factor 4936, or $120 \mathrm{~K}$ (e.g., by mutation or down-regulation mediated by antisense or RNAi constructs; McClure et al., 1999, 2000; O'Brien etal., 2002; Hancock etal., 2005), which overcomes SI, also prevents disintegration of S-RNase compartments (Goldraij et al., 2006). Furthermore, HT-B accumulates to much lower levels in non-self compared to self tubes, suggesting that destabilization of HT-B is associated with successful pollen tube growth (Goldraij et al., 2006).

On the basis of these observations, a recent model of SRNase-based SI (Fig. 4, Model 2) ascribes a major role for HT$B$ in the breakdown of S-RNase-containing compartments and release of sequestered $\mathrm{S}-\mathrm{RN}$ ases into the tube cytoplasm (Goldraij et al., 2006; McClure and Franklin-Tong, 2006). This model proposes that HT-B enters the pollen tube along with the S-RNase (as well as $120 \mathrm{~K}$ and factor 4936), and both molecules are sequestered via endocytosis into membrane-bound endosomes that fuse with vacuolar compartments. Since interaction between S-RNases and SLF presumably occurs in the cytoplasm, a small fraction of the S-RNases might exit the endomembrane system, possibly by retrograde transport into the endoplasmic reticulum and subsequent release. In non-self pollen tubes, the released S-RNases would be recognized and degraded by interaction with an unknown general S-RNase inhibitor, possibly a component of a cytoplasmic surveillance system that eliminates cytotoxic molecules. However, in self pollen tubes, allele-specific binding to cognate SLF would protect the released S-RNases from degradation and would lead to stabilization of HT-B, perhaps by SLF-mediated ubiquitination and subsequent degradation of an HT-B inhibitor. HT-B stabilization would somehow lead to endomembrane compartment breakdown, followed by en masse release of sequestered S-RNases that would be too abundant for effective general inhibitor surveillance, leaving the S-RNases active for RNA degradation. In non-self pollinations, the S-RNase-SLF interaction does not take place, HT-B is degraded and endomembrane integrity is maintained, thus keeping the majority of S-RNases sequestered and allowing pollen tube growth to proceed.

\section{Future prospects}

A major insight obtained from the molecular analysis of a handful of SI systems was the realization that SI evolved multiple times during flowering plant evolution and that different plant families use distinct molecules for recognition of self and different biochemical pathways to arrest self pollen tube development. Despite the substantial progress made in recent years, there are still glaring gaps in our understanding of SI mechanisms. While working models have been generated for each of the three SI systems reviewed here, it is still not possible, in any system, to explain exactly how recognition of self pollen by cells of the pistil translates into inhibition of pollen tube growth and ultimately, of self-fertilization.

New data generated by ongoing studies will no doubt require refinement of some models and may even cause major elements of other models to be discarded. Current research efforts are aimed at filling major gaps in each of the three SI systems, i.e., unraveling the events that are triggered subsequent to recognition in receptor-mediated crucifer and S-RNase-based SI, and identifying the male determinant of SI and determining if it interacts directly or indirectly with the stigmatic S protein in poppy. These are not the only remaining unresolved issues, however. In all three systems, very little is known about the basis of $\mathrm{SI}$ specificity in pistil and pollen determinants. Identifying the amino acid residues that determine specificity has proven difficult because of the extreme polymorphisms of $S$-locus proteins, not all of which are critical for specificity. To date, specificity-determining residues have been identified and experimentally validated for only two SCR variants in Brassica (Chookajorn et al., 2004; Sato et al., 2004), one S-RNase in Solanum (Matton et al., 1997), and no stigmatic $S$ proteins in poppy. Compounding the difficulty of these studies is the finding that different amino-acid residues appear to determine the specificity of different variants, at least in the case of SCR (Chookajorn et al., 2004). Irrespective of these difficulties, however, progress on this front is critical. Only then might it be possible to address the challenging question of how pistil and pollen SI determinants co-evolve to maintain their interaction and their competence for self recognition, and to solve the puzzle of how the large repertoire of SI specificities that exist in self-incompatible species is generated.

\section{Acknowledgements}

Work in the authors' laboratory is supported by grants from the US National Science Foundation, Department of Agriculture, and National Institutes of Health.

\section{References}

AZEVEDO, C., SANTOS-ROSA, M.J. and SHIRASU, K. (2001). The U-box protein family in plants. Trends Plant Sci. 6: 354-358.

BOOY, G., KRENS, F.A. and BINO, R.J. (1992). Analysis of pollen-tube growth in cultured maize silks. Sex. Plant Reprod. 5: 227-231.

BOWER, M.S., MATIAS, D.D., FERNANDES-CARVALHO, E., MAZZURCO, M., GU, T., ROTHSTEIN, S.J. and GORING, D.R. (1996). Two Members of the Thioredoxin-h Family Interact with the Kinase Domain of a Brassica $S$ Locus 
Receptor Kinase. Plant Cel/8: 1641-1650.

CABRILLAC, D., COCK, J.M., DUMAS, C. and GAUDE, T. (2001). The Slocus receptor kinase is inhibited by thioredoxins and activated by pollen coat proteins. Nature 410: 220-223.

CHOOKAJORN, T., KACHROO, A., RIPOLL, D.R., CLARK, A.G. and NASRALLAH, J.B. (2004). Specificity determinants and diversification of the Brassica selfincompatibility pollen ligand. Proc. Natl. Acad. Sci. USA 101: 911-917.

DARWIN, C. (1876). The effects of cross and self fertilisation in the vegetable kingdom. J. Murray, London.

DICKINSON, H. (1995). Dry stigmas, water and self-incompatibility in Brassica. Sex. Plant Reprod. 8: 1-10.

EBERT, P.R., ANDERSON, M.A., BERNATZKY, R., ALTSCHULER, M. and CLARKE, A.E. (1989). Genetic Polymorphism of Self-Incompatibility in Flowering Plants. Cel/56: 255-262.

FRANKLIN-TONG, V.E., HOLDAWAY-CLARKE, T.L., STRAATMAN, K.R., KUNKEL, J.G. and HEPLER, P.K. (2002). Involvement of extracellular calcium influx in the self-incompatibility response of Papaver rhoeas. Plant J. 29: 333345.

GEITMANN, A. (1999). Cell Death of Self-Incompatible Pollen Tubes: Necrosis or Apoptosis? InFertilization in Higher Plants: Molecular and Cytological Aspects. Cresti, M., Cai, G. and Moscatelli, A. [eds.], Springer-Verlag, Berlin, Heidelberg, New York. 113-137.

GIRANTON, J.-L., DUMAS, C., COCK, J.M. and GAUDE, T. (2000). The integral membrane $S$-locus receptor kinase of Brassica has serine/threonine kinase activity in a membranous environment and spontaneously forms oligomers in planta. Proc. Natl. Acad. Sci. USA 97: 3759-3764.

GOLDRAIJ, A., KONDO, K., LEE, C.B., HANCOCK, C.N., SIVAGURU, M., VAZQUEZ-SANTANA, S., KIM, S., PHILLIPS, T.E., CRUZ-GARCIA, F. and MCCLURE, B. (2006). Compartmentalization of S-RNase and HT-B degradation in self-incompatible Nicotiana. Nature 439: 805-810.

DE GRAAF, B.H.J., RUDD, J.J., WHEELER, M.J., PERRY, R.M., BELL, E.M., OSMAN, K., FRANKLIN, F.C.H. and FRANKLIN-TONG, V.E. (2006). Selfincompatibility in Papavertargets soluble inorganic pyrophosphatases in pollen. Nature 444: 490-493.

GU, T., MAZZURCO, M., SULAMAN, W., MATIAS, D.D. and GORING, D.R. (1998). Binding of an arm repeat protein to the kinase domain of the $S$-locus receptor kinase. Proc. Natl. Acad. Sci. USA 95: 382-387.

HAFFANI, Y.Z., GAUDE, T., COCK, J.M. and GORING, D.R. (2004). Antisense suppression of thioredoxin $h$ mRNA in Brassica napus $c v$. Westar pistils causes a low level constitutive pollen rejection response. Plant Mol. Biol. 55: 619-630.

HANCOCK, C.N., KENT, L. and MCCLURE, B.A. (2005). The stylar $120 \mathrm{kDa}$ glycoprotein is required for $\mathcal{S}$-specific pollen rejection in Nicotiana. Plant J. 43: 716-723.

HEARN, M.J., FRANKLIN, F.C.H. and RIDE, J.P. (1996). Identification of a membrane glycoprotein in pollen of Papaver rhoeas which binds stigmatic selfincompatibility (S-) proteins. Plant J. 9: 467-475.

HUA, Z. and KAO, T.-H. (2006). Identification and Characterization of Components of a Putative Petunia S-Locus F-Box-Containing E3 Ligase Complex Involved in S-RNase-Based Self-Incompatibility. Plant Cel/18: 2531-2553.

JORDAN, N.D., FRANKLIN, F.C.H. and FRANKLIN-TONG, V.E. (2000). Evidence for DNA fragmentation triggered in the self-incompatibility response in pollen of Papaver rhoeas. Plant J. 23: 471-479.

JORDAN, N.D., KAKEDA, K., CONNER, A., RIDE, J.P., FRANKLIN-TONG, V.E. and FRANKLIN, F.C.H. (1999). S-protein mutants indicate a functional role for SBP in the self-incompatibility reaction of Papaver rhoeas. Plant J. 20:119-125.

KACHROO, A., SCHOPFER, C.R., NASRALLAH, M.E. and NASRALLAH, J.B. (2001). Allele-Specific Receptor-Ligand Interactions in Brassica Self-Incompatibility. Science 293: 1824-1826.

LAI, Z., MA, W., HAN, B., LIANG, L., ZHANG, Y., HONG, G. and XUE, Y. (2002). An F-box gene linked to the self-incompatibility $(S)$ locus of Antirrhinum is expressed specifically in pollen and tapetum. Plant Mol. Biol. 50: 29-42.

LEE, H.-S., HUANG, S. and KAO, T.-H. (1994). S proteins control rejection of incompatible pollen in Petunia inflata. Nature 367: 560-563.

LIND, J.L., BÖNIG, I., CLARKE, A.E. and ANDERSON, M.A. (1996). A stylespecific $120-k$ Da glycoprotein enters pollen tubes of Nicotiana alatain vivo. Sex.
Plant Reprod. 9: 75-86.

LIU, P., SHERMAN-BROYLES, S., NASRALLAH, M.E. and NASRALLAH, J.B. (2007). A Cryptic Modifier Causing Transient Self-Incompatibility in Arabidopsis thaliana. Curr. Biol. 17: 734-740.

LUSH, W.M. and CLARKE, A.E. (1997). Observations of pollen tube growth in Nicotiana alata and their implications for the mechanism of self-incompatibility. Sex. Plant Reprod. 10: 27-35.

LUU, D.-T., QIN, X., MORSE, D. and CAPPADOCIA, M. (2000). S-RNase uptake by compatible pollen tubes in gametophytic self-incompatibility. Nature 407: 649-651.

MATTON, D.P., MAES, O., LAUBLIN, G., XIKE, Q., BERTRAND, C., MORSE, D. and CAPPADOCIA, M. (1997). Hypervariable Domains of Self-Incompatibility RNases Mediate Allele-Specific Pollen Recognition. Plant Cel/9: 1757-1766.

MCCLURE, B., MOU, B., CANEVASCINI, S. and BERNATZKY, R. (1999). A small asparagine-rich protein required for $\mathrm{S}$-allele-specific pollen rejection in Nicotiana. Proc. Natl. Acad. Sci. USA 96: 13548-13553.

MCCLURE, B.A., CRUZ-GARCIA, F., BEECHER, B. and SULAMAN, W. (2000). Factors Affecting Inter- and Intra-specific Pollen Rejection in Nicotiana. Ann. Bot. 85 Suppl. A: 113-123.

MCCLURE, B.A. and FRANKLIN-TONG, V. (2006). Gametophytic self-incompatibility: understanding the cellular mechanisms involved in "self" pollen tube inhibition. Planta 224: 233-245.

MCCLURE, B.A., GRAY, J.E., ANDERSON, M.A. and CLARKE, A.E. (1990). Selfincompatibility in Nicotiana alata involves degradation of pollen rRNA. Nature 347: 757-760.

MCCLURE, B.A., HARING, V., EBERT, P.R., ANDERSON, M.A., SIMPSON, R.J., SAKIYAMA, F. and CLARKE, A.E. (1989). Style self-incompatibility gene products of Nicotiana alata are ribonucleases. Nature 342: 955-957.

MCCORMICK, S. (2004). Control of Male Gametophyte Development. Plant Cel/16 Suppl.: S142-S153.

MURASE, K., SHIBA, H., IWANO, M., CHE, F.-S., WATANABE, M., ISOGAI, A. and TAKAYAMA, S. (2004). A Membrane-Anchored Protein Kinase Involved in Brassica Self-Incompatibility Signaling. Science 303: 1516-1519.

MURFETT, J., ATHERTON, T.L., MOU, B., GASSER, C.S. and MCCLURE, B.A. (1994). S-RNase expressed in transgenic Nicotiana causes $S$-allele-specific pollen rejection. Nature 367: 563-566.

NAITHANI, S., CHOOKAJORN, T., RIPOLL, D.R. and NASRALLAH, J.B. (2007). Structural modules for receptor dimerization in the $S$-locus receptor kinase extracellular domain. Proc. Natl. Acad. Sci. USA 104: 12211-12216.

NASRALLAH, J.B. (2000). Cell-cell signaling in the self-incompatibility response. Curr. Opin. Plant Biol. 3: 368-373.

NASRALLAH, J.B. (2005). Recognition and rejection of self in plant self-incompatibility: comparisons to animal histocompatibility. Trends Immunol. 26: 412-418.

NASRALLAH, M.E., LIU, P. and NASRALLAH, J.B. (2002). Generation of SelfIncompatible Arabidopsis thaliana by Transfer of Two $S$ locus Genes from $A$. lyrata. Science 297: 247-249.

NASRALlAH, M.E., LIU, P., SHERMAN-BROYLES, S., BOGGS, N. and NASRALLAH, J.B. (2004). Natural variation in expression of self-incompatibility in Arabidopsis thaliana: Implications for the evolution of selfing. Proc. Natl. Acad. Sci. USA 101: 16070-16074.

DE NETTANCOURT, D. (2001). Incompatibility and Incongruity in Wild and Cultivated Plants, $2^{\text {nd }}$ ed. Springer-Verlag, Berlin, Heidelberg, New York.

O'BRIEN, M., KAPFER, C., MAJOR, G., LAURIN, M., BERTRAND, C., KONDO, K., KOWYAMA, Y. and MATTON, D.P. (2002). Molecular analysis of the stylarexpressed Solanum chacoense small asparagine-rich protein family related to the HT modifier of gametophytic self-incompatibility in Nicotiana. Plant J. 32: 985-996.

QIAO, H., WANG, H., ZHAO, L., ZHOU, J., HUANG, J., ZHANG, Y. and XUE, Y. (2004). The F-box Protein AhSLF-S ${ }_{2}$ Physically Interacts with S-RNases That May Be Inhibited by the Ubiquitin/26S Proteasome Pathway of Protein Degradation During Compatible Pollination in Antirrhinum. Plant Cel/16: 582-595.

RAVEN, P.H., EVERT, R.F. and EICHHORN, S.E. (2005). Biology of Plants, $7^{\text {th }}$ ed. W.H. Freeman and Company, New York, NY.

REISER, L. and FISCHER, R.L. (1993). The Ovule and the Embryo Sac. Plant Cell 5: 1291-1301. 
RUDD, J.J., FRANKLIN, F.C.H., LORD, J.M. and FRANKLIN-TONG, V.E. (1996). Increased Phosphorylation of a $26-\mathrm{kD}$ Pollen Protein Is Induced by the SelfIncompatibility Response in Papaver rhoeas. Plant Cel/8: 713-724.

RUDD, J.J., OSMAN, K., FRANKLIN, F.C.H. and FRANKLIN-TONG, V.E. (2003). Activation of a putative MAP kinase in pollen is stimulated by the self-incompatibility (SI) response. FEBS Lett. 547: 223-227.

SATO, Y., OKAMOTO, S. and NISHIO, T. (2004). Diversification and Alteration of Recognition Specificity of the Pollen Ligand SP11/SCR in Self-Incompatibility of Brassica and Raphanus. Plant Cel/16: 3230-3241.

SCHOPFER, C.R., NASRALLAH, M.E. and NASRALLAH, J.B. (1999). The Male Determinant of Self-Incompatibility in Brassica. Science 286: 1697-1700.

SHIMOSATO, H., YOKOTA, N., SHIBA, H., IWANO, M., ENTANI, T., CHE, F.-S., WATANABE, M., ISOGAI, A. and TAKAYAMA, S. (2007). Characterization of the SP11/SCR High-Affinity Binding Site Involved in Self/Nonself Recognition in Brassica Self-Incompatibility. Plant Cel/19: 107-117.

SIJACIC, P., WANG, X., SKIRPAN, A.L., WANG, Y., DOWD, P.E., MCCUBBIN, A.G., HUANG, S. and KAO, T.-H. (2004). Identification of the pollen determinant of S-RNase-mediated self-incompatibility. Nature 429: 302-305.

SNOWMAN, B.N., KOVAR, D.R., SHEVCHENKO, G., FRANKLIN-TONG, V.E. and STAIGER, C.J. (2002). Signal-Mediated Depolymerization of Actin in Pollen during the Self-Incompatibility Response. Plant Cel/14: 2613-2626.

SONNEVELD, T., TOBUTT, K.R., VAUGHAN, S.P. and ROBBINS, T.P. (2005). Loss of Pollen-SFunction in Two Self-Compatible Selections of Prunus avium Is Associated with Deletion/Mutation of an $S$ Haplotype-Specific F-Box Gene. Plant Cel/17: 37-51.

STEIN, J.C., DIXIT, R., NASRALLAH, M.E. and NASRALLAH, J.B. (1996). SRK, the Stigma-Specific S Locus Receptor Kinase of Brassica, Is Targeted to the Plasma Membrane in Transgenic Tobacco. Plant Cel/8: 429-445.

STEIN, J.C., HOWLETT, B., BOYES, D.C., NASRALLAH, M.E. and NASRALLAH, J.B. (1991). Molecular cloning of a putative receptor protein kinase gene encoded at the self-incompatibility locus of Brassica oleracea. Proc. Natl. Acad. Sci. USA 88: 8816-8820.

STONE, S.L., ANDERSON, E.M., MULLEN, R.T. and GORING, D.R. (2003). ARC1
Is an E3 Ubiquitin Ligase and Promotes the Ubiquitination of Proteins during the Rejection of Self-Incompatible Brassica Pollen. Plant Cel/15: 885-898.

SUZUKI, G., KAI, N., HIROSE, T., FUKUI, K., NISHIO, T., TAKAYAMA, S., ISOGAI, A., WATANABE, M. and HINATA, K. (1999). Genomic Organization of the $S$ Locus: Identification and Characterization of Genes in SLG/SRKRegion of $S^{9}$ Haplotype of Brassica campestris (syn. rapa). Genetics 153: 391-400.

TAKASAKI, T., HATAKEYAMA, K., SUZUKI, G., WATANABE, M., ISOGAI, A. and HINATA, K. (2000). The $S$ receptor kinase determines self-incompatibility in Brassica stigma. Nature 403: 913-916.

TAKAYAMA, S. and ISOGAI, A. (2005). Self-Incompatibility in Plants. Annu. Rev. Plant Biol. 56: 467-489.

TAKAYAMA, S., SHIMOSATO, H., SHIBA, H., FUNATO, M., CHE, F.-S., WATANABE, M., IWANO, M. and ISOGAI, A. (2001). Direct ligand-receptor complex interaction controls Brassica self-incompatibility. Nature 413:534-538.

THOMAS, S.G. and FRANKLIN-TONG, V.E. (2004). Self-incompatibility triggers programmed cell death in Papaverpollen. Nature 429: 305-309.

THOMAS, S.G., HUANG, S., LI, S., STAIGER, C.J. and FRANKLIN-TONG, V.E. (2006). Actin depolymerization is sufficient to induce programmed cell death in self-incompatible pollen. J. Cell Biol. 174: 221-229.

USHIJIMA, K., SASSA, H., DANDEKAR, A.M., GRADZIEL, T.M., TAO, R. and HIRANO, H. (2003). Structural and Transcriptional Analysis of the Self-Incompatibility Locus of Almond: Identification of a Pollen-Expressed F-Box Gene with Haplotype-Specific Polymorphism. Plant Cel/15: 771-781.

VANOOSTHUYSE, V., TICHTINSKY, G., DUMAS, C., GAUDE, T. and COCK, J.M. (2003). Interaction of Calmodulin, a Sorting Nexin and Kinase-Associated Protein Phosphatase with Brassica oleracea S Locus Receptor Kinase. Plant Physiol. 133: 919-929.

WATANABE, M., ITO, A., TAKADA, Y., NINOMIYA, C., KAKIZAKI, T., TAKAHATA, Y., HATAKEYAMA, K., HINATA, K., SUZUKI, G., TAKASAKI, T. et al. (2000). Highly divergent sequences of the pollen self-incompatibility $(S)$ gene in classI S haplotypes of Brassica campestris (syn. rapa) L. FEBS Lett 473: 139-144.

YADEGARI, R. and DREWS, G.N. (2004). Female Gametophyte Development. Plant Cel/16 Suppl.: S133-S141. 


\section{Related, previously published Int. J. Dev. Biol. articles}

See our recent Special Issue Developmental Biology in Poland edited by Tarkowski, Maleszewski and Kloc at: http://www.ijdb.ehu.es/web/contents.php?vol=52\&issue=2-3

See our recent Special Issue Plant Development edited by José L. Micol and Miguel A. Blázquez at: http://www.ijdb.ehu.es/web/contents.php?vol=49\&issue=5-6

Genetic control of gamete quality in the mouse - a tribute to Halina Krzanowska Jozefa Styrna

Int. J. Dev. Biol. (2008) 52: 195-199

The role of ion fluxes in polarized cell growth and morphogenesis: the pollen tube as an experimental paradigm Erwan Michard, Filipa Alves and José A. Feijó -

Int. J. Dev. Biol. (2008) 52: doi: 10.1387/ijdb.072296em

Regionalized calcium signaling in zebrafish fertilization

Dipika Sharma and William H. Kinsey

Int. J. Dev. Biol. (2008) 52: 561-570

The making of gametes in higher plants

Leonor C. Boavida, Jörg D. Becker and José A. Feijó

Int. J. Dev. Biol. (2005) 49: 595-614

Gametophyte interaction and sexual reproduction: how plants make a zygote Leonor C. Boavida, Ana Maria Vieira, Jörg D. Becker and José A. Feijó Int. J. Dev. Biol. (2005) 49: 615-632

Regulated RNA processing in the control of Arabidopsis flowering Victor Quesada, Caroline Dean and Gordon G. Simpson

Int. J. Dev. Biol. (2005) 49: 773-780

\section{Environmental regulation of flowering}

Israel Ausín, Carlos Alonso-Blanco and José-Miguel Martínez-Zapater Int. J. Dev. Biol. (2005) 49: 689-705

Flower and fruit development in Arabidopsis thaliana

Pedro Robles and Soraya Pelaz

Int. J. Dev. Biol. (2005) 49: 633-643

Flower symmetry and shape in Antirrhinum

Jorge Almeida and Lisete Galego

Int. J. Dev. Biol. (2005) 49: 527-537

Egg-jelly signal molecules for triggering the acrosome reaction in starfish spermatozoa.

M Hoshi, T Nishigaki, A Ushiyama, T Okinaga, K Chiba and M Matsumoto Int. J. Dev. Biol. (1994) 38: 167-174

Post-fertilization changes in Discoglossus pictus (Anura) eggs result in the formation of a capsular chamber where the egg rotates.

C Campanella, F Amore, G Pitari, C Fusco, G Maurizi and S Dupré

Int. J. Dev. Biol. (1992) 36: 413-422

2006 ISI **Impact Factor $=3.577^{* *}$

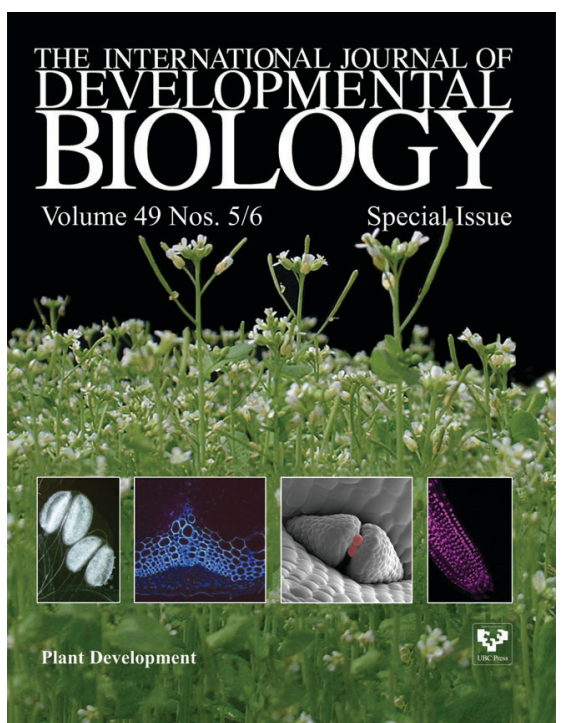

